\title{
Exergy Analysis of a Double-Effect Solar Absorption Refrigeration System in Ngaoundere
}

\author{
Maurice Tenkeng1,2, Paiguy Armand Ngouateu Wouagfack ${ }^{3 *}$, Réné Tchinda2,3 \\ ${ }^{1}$ Department of Physics, University of Dschang, Dschang, Cameroon \\ ${ }^{2}$ LISIE, University Institute of Technology Fotso Victor, University of Dschang, Dschang, Cameroon \\ ${ }^{3}$ Department of Renewable Energy, Higher Technical Teachers' Training College, University of Buea, \\ Kumba, Cameroon \\ Email: *ngouateupaiguy@yahoo.fr
}

How to cite this paper: Tenkeng, M., Wouagfack, P.A.N. and Tchinda, R. (2019) Exergy Analysis of a Double-Effect Solar Absorption Refrigeration System in Ngaoundere. World Journal of Engineering and Technology, 7, 158-174.

https://doi.org/10.4236/wjet.2019.71011

Received: September 2, 2018

Accepted: February 11, 2019

Published: February 14, 2019

Copyright (C) 2019 by author(s) and Scientific Research Publishing Inc. This work is licensed under the Creative Commons Attribution International License (CC BY 4.0)

http://creativecommons.org/licenses/by/4.0/

\begin{abstract}
Solar energy is replacing more and more traditional sources of energy because of the fact that it's also fighting about global warming. This study is based on exergy analysis of a double-effect series flow absorption refrigeration system powered by solar energy in Ngaoundere. The simulation is done on the basis of a half hourly analysis for the first time, from 6.30 AM to 6.30 PM, using water-lithium bromide as working pair. The main parameters for the performance of an absorption cycle, which are the COP and the ECOP, have been analyzed and the results show that this two parameters increase while increasing the temperature of the main generator. The exergy loss of each component of the system and the total exergy loss of the system have been analyzed and their effectiveness calculated, using the first and second law of thermodynamics. The highest exergy loss occurs in the main generator GI and in the absorber, making these components more important in an absorption cycle. This analysis is based on a mathematical model using FORTRAN language. The results obtained may be useful for the optimization of solar absorption refrigeration systems.
\end{abstract}

\section{Keywords}

Double Effect, Refrigeration, Half Hourly, Exergy Loss

\section{Introduction}

Refrigeration is one of the active cooling methods studied here to enable nu- 
merous villages from remote areas and why not towns, to benefit from welfare offered by nature; areas where electricity is in short supply are also concerned. Refresh air or refrigeration is becoming more and more important in the daily activities nowadays. The refrigerators are useful for making ice, for storing vaccines and food in areas where electricity is unavailable or high in cost that is the case in Africa in general and Cameroon in particular. Passive cooling systems, that is: good insulation, double glazing or use of thermal mass and ventilation are no longer sufficient. In inter-tropical regions, with the sun available all the yearlong, solar energy has a considerable interest because of the promising advantages. The First solar refrigeration system was introduced by Ferdinand Carré in 1895 [1]. Double-effect absorption refrigeration cycle was introduced for the first time in 1956 for developing the system performance within a heat source at high temperature [2].

In order to improve the performance of a solar absorption refrigeration system, number optimization studies based on the energy analysis have been done. Energy analysis takes into account the first law of thermodynamics which deals with the conversion of energy; this cannot show where the irreversibility occurs in a system that has many sources of energy [3].

The exergy analysis based on the second law of thermodynamics, is the only way to detect irreversibility in different components of the system that is the only rational basis for evaluating the system performance [4].

Many researchers have carry out studies on exergy analysis of double-effect refrigeration systems. K. Talukdar et al. [5] performed an exergy analysis to show the performance variation of both the topping PC and the bottoming ARS with changing $\mathrm{HPG}$ temperature from $120^{\circ} \mathrm{C}$ to $150^{\circ} \mathrm{C}$. S.A.M Said et al. [6] brought two modifications to the traditional solar absorption refrigeration system by recovering waste heat from dephlegmator and utilization of a refrigerant storage unit. The COP increases $18 \%$ because of these modifications. The exergy variation of a solar assisted double-effect absorption refrigeration system, was studied in detail and the parameters of the cycle analyzed by Ravikumar T.S et al. [7] on the basis of first and second law effectiveness and the results indicated that a better quality of the evaporator, has more effect on the system performance than the better quality of other components. The study of Nahla Bouazis et al. [8] reveals that, the performance of a novel configuration is better than that of the two stage conventional configuration and it allows a lower temperature, about $60^{\circ} \mathrm{C}-120^{\circ} \mathrm{C}$ instead of $100^{\circ} \mathrm{C}-160^{\circ} \mathrm{C}$ for conventional cycle. T. Avanessian et al. [9] analysed and compared different water-cooled $\mathrm{LiBr}-\mathrm{H}_{2} \mathrm{O}$ absorption systems under different operating and climatic conditions, and the effect of considering the chemical exergy of the $\mathrm{LiBr}-\mathrm{H}_{2} \mathrm{O}$ solution on the second law analysis of such a system is probed. Milad Ashouri et al. [10] examined the performance of a double pressure organic Rankine cycle couple with a solar collector, via a thermal tank during a day. Results showed that the system is capable of generating stable power during the day with a solar fraction of $100 \%$. Kai Zhang 
et al. [11] discussed in detail the exergy loss for each component, in order to identify the inefficient components and then to indicate the way to improve the performance of a double-effect evaporating temperature chiller. Rabah Gomri [12] investigated the potential of application of a single effect and multiple effect absorption cooling systems for the production of chilled water. The simulation results were used to study the influence of the varios operating parameters on the performance of single, double and triple effect absorption cooling cycles. Omer Kaynakli et al. [13] investigated the equation temperature of the overall system and its components by conducting a parametric study on heat capacity and exergy destruction of the HPG, coefficient of performance (COP) of the system and mass flow rate of heat sources. R. Maryami et al. [14] done a comparative study between the five classes of $\mathrm{LiBr} /$ water absorption refrigeration systems to investigate the influence of various operating parameters on the coefficient of performance. Zeyu Li et al. [15] give the yearly performance analysis of a solar air cooled double effect $\mathrm{LiBr} / \mathrm{H}_{2} \mathrm{O}$ absorption cooling system in subtropical city, including total efficiency, cooling capacity per area of collector and solar fraction. Ahmed Hamed et al. [16] optimized the coefficient of performance of a double-effect absorption system and predicted the coefficient of performance and exergetic efficiency of the system with two equations developed. Rabah Gomri et al. [17] simulated a double-effect vapor absorption cooler system to calculate exergy losses, the coefficient of performance and the number of exergy of each component. A. Allouhi et al. [1] presented a review of the available Technologies to provide cooling from solar energy for both thermal and photovoltaic ways. A market study is also carried out to evidence the potentiel of these solar cooling technologies with overview of the various solar cooling installations in Europe, Egypt and China was also presented. S.W Sharshir et al. [18] highlighted design methods to allow the researchers to optimize the solar still further development and proposed some recommendations.

In this study, in order to analyse the system with a great accuracy, we decided to look more closely by the simulation of a half hour analysis, from 6:30 AM to 6:30 PM of a double effect series flow absorption refrigeration system, using water-lithium bromide solution as working fluid with an Evacuated tube solar collector type. The data, which are solar insolation and environmental temperature are taken from M. Tenkeng et al. [19] and were collected on the 15th of January 2014, in Ngaoundere, Cameroon. The main focus of this study is concentrated on the exergy analysis of each component of the system, precisely the exergy loss [20]. The coefficient of performance (COP) and the exergetic coefficient of performance (ECOP) of the system are also investigated.

\section{Description of the Model and Assumptions}

\subsection{Description of a Series Flow Solar Absorption Cycle}

Double-effect consists of components similar as in single-effect absorption system with an additional generator, see Figure 1 . The weak solution at state 1 is 
pumped from the absorber to the first-effect solar assisted generator (GI) through two heat exchangers (HEX I and HEX II). The $\mathrm{LiBr}-\mathrm{H}_{2} \mathrm{O}$ solution in the first-effect generator is heated at high temperature. This high temperature heat comes from a solar collector to supplies to the first-effect generator to boil out the water vapour from the solution. The vapour refrigerant generated is condensed at high pressure in the second-effect generator. Thus, the primary vapour, from the first-effect generator goes to the secondary condenser incorporated in the second-effect generator (GII). The heat of condensation from this condenser is utilized by the second-effect generator. The strong solution, so called because it's poor in water, which is released by the first-effect generator at state 5 flows to the second-effect generator, through HEX II where the solution is cooled to some extent by exchanging heat with the weak solution. The heat rejected is used to produce addition refrigerant vapour from the solution coming from the first-effect generator. At the outlet of the second-effect generator vapour is produced, which together with the condensed water vapour from the secondary condenser, flows into the main condenser through a throttle valve where the heat of condensation is rejected to the atmosphere. Thus, the overall amount of liquid refrigerant leaving the main condenser is the sum of refrigerant coming from the first and second-effect generators. The refrigerant in a liquid phase from this condenser, on expansion, flows to the evaporator through a throttle valve (REV) where it is evaporated at low pressure. After extracting heat from the medium to be cooled, the refrigerant evaporates and then passes to the absorber where it gets absorbed by the strong solution coming from the second-effect generator, through HEX I and a throttle valve (SEV). The resulting weak solution in the absorber is then pumped to the first-effect generator and the cycle completes.

Figure 2 shows the P-T-X diagram of our chiller. Idealy, this system has three pressure levels and five operating temperature levels which are: $T_{e} ; T_{a} ; T_{\dot{c}} T_{g I}$ and $T_{g I I}$ Low pressure prevails in the evaporator and absorber $\left(P_{1}=P_{a}=P_{e}\right.$ LPL), high pressure in the first-effect generator (GI) $\left(P_{3}=P_{G I}\right.$ HPL) and intermediate pressure in the condenser and the second-effect generator (GII) $\left(P_{2}=P_{c}=P_{G I I}\right.$ IPL).

\subsection{Assumptions}

For the simulation of the cycle, following assumptions were made [21] [22] [23]:

1) The ambient temperature is assumed to be $298.15 \mathrm{~K}$;

2) The refrigerant completely evaporates in the evaporator;

3) The thermal and pressure losses can be ignored;

4) The solution is saturated after is passes through the absorber and the generator;

5) The refrigerant vapor is completely condensed in the condenser;

6) For the temperature range considered, the absorbent is non-volatile;

7) The refrigerant leaves the condenser and evaporator at saturated state; 
8) Changes occur only at pump and pressure-reducing valves for the pressure;

9) Because thermodynamic work required change in specific volume liquid, the solution pump work is neglected;

10) In the valves, the expansion process is isenthalpic.

\section{Thermodynamic Analysis}

\subsection{Exergy Analysis of the System}

The exergy of fluid stream can be defined as [24]:

$$
\varphi=\left(h-h_{0}\right)-T_{0}\left(s-s_{0}\right)
$$

where $\varphi$ is the exergy of the fluid at temperature $T, h$ and $s$ are respectively enthalpy and entropy of the fluid, $h_{0}$ and $s_{0}$ are respectively the enthalpy and entropy of the fluid at environmental temperature $T_{0}(298.15 \mathrm{~K})$.

The specific exergy content of a mixture with $\mathrm{m}$ components is defined by A. Sözen et al. 2007 [25] as:

$$
\varphi=\sum_{n=1}^{m} x_{n} h_{n}-T_{0} \sum_{n=1}^{m} x_{n} s_{n}-\sum_{n=1}^{m} x_{n} \mu_{n 0}
$$

where $T_{0}$ is the reference temperature $\left(25^{\circ} \mathrm{C}\right), x_{n}$ is mass fraction and $\mu_{n 0}$ the chemical potential of the $n^{\text {th }}$ component of the mixture at $T_{0}$ and $P_{0}$.

The exergy loss or the availability loss in each component is given by [21]:

$$
\Delta \varphi=\sum m_{i} \varphi_{i}-\sum m_{0} \varphi_{0}-\left[\sum Q\left(1-\frac{T_{0}}{T}\right)_{i}-\sum Q\left(1-\frac{T_{0}}{T}\right)_{\text {ref }}\right]+\sum W
$$

where $\Delta \varphi$ is the lost exergy or irreversibility that occurs in the process. The first two terms of the right hand side are the exergy of the inlet and outlet streams of the control volume. The third and fourth terms are the exergy associated with the heat transferred from the source maintained at a temperature $T$. The last term is the exergy of mechanical work added to the control volume. The term is negligible for absorption systems as the solution pump has very low power requirements.

The total exergy loss of absorption system is the sum of exergy loss in each component and is written as:

$$
\Delta \varphi=\sum_{n=1}^{m} \Delta \varphi_{n}
$$

De Vos (1992) [26] established equations for calculating the exergy loss to the collector per unit area as function of the exergy emitted from the sun minus the albedo of the earth and the radiation emitted from the solar collector. The exergy analysis of the collector can be obtained with Pridasa was et al. 2004 [27]:

Exergy (radiation) input:

$$
\varphi=f \sigma T_{\text {sun }}^{4}+(1-f) \sigma T_{p}^{4}-\sigma T_{s c}^{4}
$$

where sun is for sun, $p$ for planet and $s c$ for solar collector, $f$ is the sunlight dilution factor equal to $2.16 \times 10^{-5}$ on earth. The solar radiation that reaches the 
solar collector is transformed into heat. This heat is partly absorbed by thermal fluid and the surrounding equipment and partly lost to the environment. The available solar radiation is transformed into available heat for the process, however, the second law of thermodynamics hinders the transformation of all heat into exergy [26] [27]. The exergy of the solar heat input to the solar collector is given by the relationship:

Exergy (heat) input:

$$
\varphi_{s, h}=Q_{a v a}\left(1-\frac{T_{r e f}}{T_{s c}}\right)
$$

Exergy loss during the transformation process for each component is as follows:

$$
I_{s c, r}=\varphi_{s}-\varphi_{s, h}
$$

The useful exergy gained by the solar collector is:

$$
\varphi_{s u}=Q_{u}\left(1-\frac{T_{r e f}}{T_{s c}}\right)
$$

where $Q_{u}$ is the useful steady state energy gain to the solar collector. The exergy loss from the input of solar collector to the working fluid can be calculated using the equation:

$$
\Delta \varphi_{s c}=\varphi_{s}-\varphi_{s u}-\Delta \varphi_{e n}-\Delta \varphi_{s c, r}
$$

where $\Delta \psi_{s c, r}$ is the exergy lost during the transformation from solar energy radiation to heat on the solar collector and written as [26]:

$$
\Delta \varphi_{s c, r}=\varphi_{s}-\varphi_{s, h}
$$

And $\Delta \psi_{e n}$ is the average loss caused by the wind effect on the solar collector. It's impossible to calculate a priori, since the speed, the direction and the sense of the wind are unknown [27]. Moreover, as the plate temperature is a function of $\Delta \psi_{e n}, \Delta \psi_{e n}$ cannot be determined either. For these reasons, it will be assume for simplicity $\Delta \psi_{e n}=0$ and therefore:

$$
\Delta \varphi_{s c}=\varphi_{s}-\varphi_{s u}-\Delta \varphi_{s c, r}
$$

The exergy efficiency for cooling is the ratio of the chilled water exergy at the evaporator to the exergy of the heat source at the generator:

$$
\varphi_{\text {cooling }}=\frac{m_{22}\left(\varphi_{22}-\varphi_{23}\right)}{m_{18}\left(\varphi_{18}-\varphi_{19}\right)}
$$

For the thermodynamic analysis, we have equations adapted from O. Kaynakli et al. (2007) [28]:

The mass balance:

$$
\begin{aligned}
& \dot{m}_{w}=\dot{m}_{s}+\dot{m}_{H_{2} \mathrm{O}} \\
& \dot{m}_{w} X_{w}=\dot{m}_{s} X_{s}
\end{aligned}
$$

where $X$ is the $\mathrm{LiBr}$ concentration, $w$ (weak solution) and $s$ (strong solution). 
The flow rate of the strong and weak solutions can be determined from equation below:

$$
\begin{gathered}
\dot{m}_{s}=\frac{X_{w}}{X_{s}-X_{w}} \dot{m}_{H_{2} O} \\
\dot{m}_{w}=\frac{X_{s}}{X_{s}-X_{w}} \dot{m}_{H_{2} O}
\end{gathered}
$$

The double circulation ratios have been defined in the cycle as:

$$
f_{1}=\frac{X w}{X_{s 1}-X_{w}}=\frac{X_{1}}{X_{5}-X_{1}} \text { and } f_{2}=\frac{X_{s 1}}{X_{s 2}-X_{s 1}}=\frac{X_{5}}{X_{14}-X_{5}}
$$

Using circulation ratios, the heat capacity of each component is: For the generators

$$
\begin{gathered}
Q_{G I}=h_{10}+f_{1} h_{5}-\left(f_{1}+1\right) h_{17} \\
Q_{G I I}=\left(f_{2}\left(f_{1}+1\right)\right) h_{13}-f_{2} h_{9}+f_{1}\left(f_{2} /\left(f_{1}+1\right)\right) h_{14}
\end{gathered}
$$

For the condenser

$$
Q_{C}=\left(f_{2} /\left(f_{1}+1\right)\right) h_{13}-\left(f_{2} /\left(f_{1}+1\right)+1\right) h_{15}
$$

For the evaporator

$$
Q_{E}=\left(\left(f_{2} /\left(f_{1}+1\right)\right)+1\right)\left(h_{17}-h_{16}\right)
$$

For the absorber

$$
Q_{A}=\left(f_{2} /\left(f_{1}+1\right)\right) h_{17}+\left(\left(f_{21} f_{1}\right) /\left(f_{1}+1\right)\right) h_{7}-\left(f_{2}+1\right) h_{1}
$$

For the heat exchangers

$$
\begin{aligned}
Q_{H E X I} & =\left(f_{2}+1\right)\left(h_{3}-h_{2}\right) \\
Q_{\text {HEXII }} & =\left(f_{2}+1\right)\left(h_{4}-h_{3}\right)
\end{aligned}
$$

The pump work can be expressed as:

$$
W_{p}=v_{w s}\left(P_{G I I}-P_{E}\right)\left(f_{2}+1\right) / \eta_{p}
$$

The coefficient of performance for the system is given by:

For the exergy destruction, the following equations are determined as:

For the generators

$$
\begin{gathered}
I_{G I}=\dot{m}\left(\varphi_{10}\left(f_{2}+1\right)-\varphi_{5} f_{2}-\varphi_{10}\right)+\dot{m_{18}}\left(\varphi_{18}-\varphi_{19}\right) \\
I_{G I I}=\dot{m_{10}}\left(\varphi_{9} f_{2}-\phi_{13}\left(f_{2} /\left(f_{1}+1\right)\right)-\varphi_{14}\left(f_{1}\left(f_{2} /\left(f_{1}+1\right)\right)\right)\right)+\dot{m_{10}}\left(\varphi_{10}-\varphi_{11}\right)
\end{gathered}
$$

For the condenser

$$
I_{C}=\dot{m}_{10}\left(\varphi_{13}\left(f_{2} /\left(f_{1}+1\right)\right)+\varphi_{12}-\varphi_{15}\left(f_{2} /\left(f_{1}+1\right)\right)\right)+\dot{m_{20}}\left(\varphi_{20}-\varphi_{21}\right)
$$

For the evaporator

$$
I_{E}=\stackrel{\dot{m}}{m_{10}}\left(\left(f_{2} /\left(f_{1}+1\right)\right)+1\right)\left(\varphi_{16}-\varphi_{17}\right)+\dot{m} 2\left(\varphi_{22}-\varphi_{23}\right)
$$


For the absorber

$$
I_{A}=\stackrel{;}{m_{10}}\left(\left(\varphi_{17}\left(f_{2} /\left(f_{1}+1\right)\right)+1\right)+\varphi_{7}\left(\left(f_{2} f_{1}\right) /\left(f_{1}+1\right)\right)-\varphi_{1}\left(f_{2}+1\right)\right)+m_{24}\left(\varphi_{24}-\varphi_{25}\right)
$$

For the throttle valves

$$
\begin{gathered}
I_{R E V}=\stackrel{;}{m_{10}}\left(\left(f_{2} /\left(f_{1}+1\right)\right)+1\right)\left(\varphi_{15}-\varphi_{16}\right) \\
I_{S E V}=m_{10}^{;} f_{2}\left(\varphi_{6}-\varphi_{7}\right)
\end{gathered}
$$

For the heat exchangers

$$
\begin{gathered}
I_{H E X I}=\stackrel{;}{m_{10}}\left(\left(f_{1}+1\right)\right)\left(\varphi_{2}-\varphi_{3}\right)+\left(f_{1} f_{2}\right) /\left(f_{2}+1\right)\left(\varphi_{6}-\varphi_{14}\right) \\
I_{H E X I I}=m_{10}^{;}\left(f_{2}\left(\varphi_{5}-\varphi_{8}\right)+\left(f_{2}+1\right)\left(\varphi_{3}-\varphi_{4}\right)\right)
\end{gathered}
$$

For the pump

$$
I_{\text {PUMP }}={\stackrel{;}{m_{10}}}\left(f_{1}+1\right)\left(\varphi_{1}-\varphi_{2}\right)
$$

The total exergy destruction for all the system is:

$$
I_{S}=I_{G I}+I_{G I I}+I_{C}+I_{A}+I_{E}+I_{R E V}+I_{S E V}+I_{H E X I}+I_{H E X I I}+I_{P U M P}
$$

A. Sözen et al. 2007 [27] defined the exergetic coefficient of performance on which depends the effectiveness of an ARS:

$$
\text { ECOP }=\frac{\dot{q}_{e}\left(1-\frac{T_{0}}{T_{e}}\right)}{\dot{q}_{g}\left(1-\frac{T_{0}}{T_{g}}\right)+\dot{W}_{p e}}=\frac{m_{17}\left(\varphi_{17}-\varphi_{16}\right)}{m_{4} \varphi_{4}+m_{10} \varphi_{10}-m_{5} \varphi_{5}}
$$

And the coefficient of performance of the system for cooling purpose is:

$$
C O P=\frac{\dot{q}_{e}}{\dot{q}_{g}}=\frac{m_{17}\left(h_{17}-h_{16}\right)}{m_{4} h_{4}+m_{10} h_{10}-m_{5} h_{5}}
$$

\subsection{Input Parameters for the Simulation}

To simulate the above equations, a simulation program written in FORTRAN was developed. Properties of the $\mathrm{LiBr}-\mathrm{H}_{2} \mathrm{O}$ solution and typical overall heat transfer coefficient were adopted from Gur Mittelman 2007 [29]. Also, the solar insolation and the ambient temperature, the solution mass flow rate and the solution concentration are given in Table 1.

The cooling load of the system is $Q_{E}=10 \mathrm{kw}$ and the evaporator temperature is $T_{E}=6^{\circ} \mathrm{C}$, the reference temperature is $T_{0}=25^{\circ} \mathrm{C}$. The temperature of the cooling water in the absorber and the condenser is $3^{\circ} \mathrm{C}$. The solar collector is a flate plate collector with $60^{\circ}$ angle of incidence and $100 \mathrm{~m}^{2}$ of area. Properties of the $\mathrm{LiBr}-\mathrm{H}_{2} \mathrm{O}$ solution and typical overall heat transfer coefficient were adopted from Gur Mittelman [29]. For the heat transfer area or total conductance, we adopted the values from $\mathrm{M}$. Tenkeng et al. [19]: (UA)a $=1.800 \mathrm{~kW} / \mathrm{K},(\mathrm{UA}) \mathrm{e}=$ $2.250 \mathrm{~kW} / \mathrm{K},(\mathrm{UA}) \mathrm{g}=1.000 \mathrm{~kW} / \mathrm{K},(\mathrm{UA}) \mathrm{c}=1.200 \mathrm{~kW} / \mathrm{K}$. 


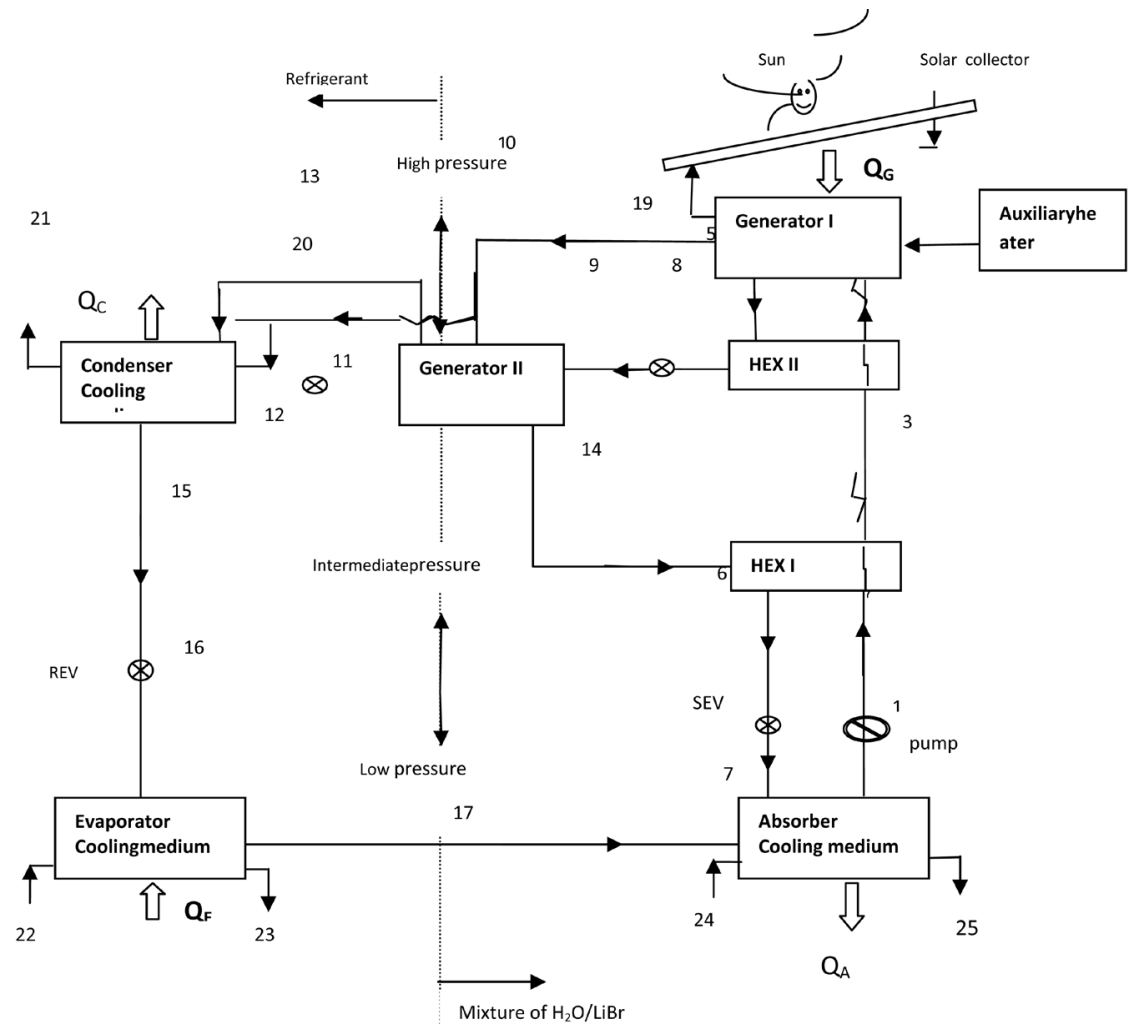

Figure 1. Doubleeffectserie flow solarabsorptionrefrigerartionchiller.

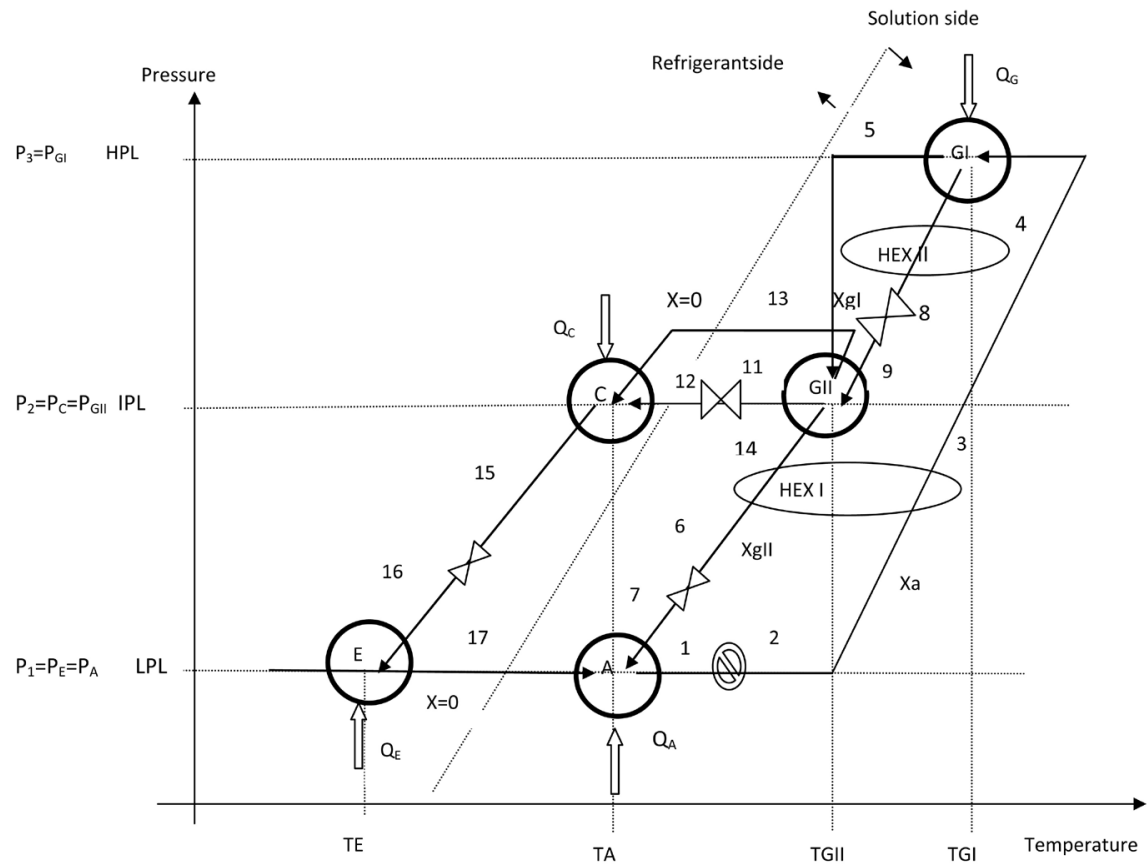

Figure 2. P-T-X diagram of double effect series flow absorptionregfrigerationcycle.

\section{Results and Discussion}

To have a better understanding of the results and their interpretations, thermodynamics properties of each point of the entired system are given in Tables 1-4. 
Table 1. Ambient temperature and Solar insolation in Ngaoundere on the 15th of January 2014 [19].

\begin{tabular}{|c|c|c|}
\hline Temperature & Solar insolation $\left(\mathrm{W} / \mathrm{m}^{2}\right)$ & Hour \\
\hline 25.4125 & 29.126 & 6.30 \\
\hline 26.875 & 153.846 & 7.00 \\
\hline 28.184 & 218.446 & 7.30 \\
\hline 28.375 & 326.923 & 8.00 \\
\hline 29.737 & 422.330 & 8.30 \\
\hline 29.875 & 528.846 & 9.00 \\
\hline 31.097 & 635.922 & 9.30 \\
\hline 31.3 & 750 & 10.00 \\
\hline 31.75 & 815.534 & 10.30 \\
\hline 32.3125 & 865.385 & 11.00 \\
\hline 32.6875 & 907.766 & 11.30 \\
\hline 33.0625 & 932.6923 & 12.00 \\
\hline 33.25 & 946.602 & 12.30 \\
\hline 33.4375 & 951.923 & 13.00 \\
\hline 33.625 & 936.893 & 13.30 \\
\hline 33.4375 & 875 & 14.00 \\
\hline 33.25 & 830.097 & 14.30 \\
\hline 32.875 & 721.154 & 15.00 \\
\hline 32.6875 & 616.504 & 15.30 \\
\hline 32.50 & 509.615 & 16.00 \\
\hline 32.3125 & 393.204 & 16.30 \\
\hline 32.125 & 298.077 & 17.00 \\
\hline 31.75 & 174.175 & 17.30 \\
\hline 31.5625 & 134.615 & 18.00 \\
\hline 31.0 & 53.398 & 18.30 \\
\hline
\end{tabular}

Table 2. The four level temperature at 12.30 PM.

\begin{tabular}{cc}
\hline Component & Temperature $\left({ }^{\circ} \mathrm{C}\right)$ \\
\hline Evaporator $T_{E}$ & 6 \\
Condenser $T_{C}$ & 35 \\
Absorber $T_{A}$ & 35 \\
Second effect generator $T_{G I I}$ & 81.45 \\
First effect generator $T_{G I}$ & 137.10 \\
\hline
\end{tabular}

Table 1 gives the solar insolation and the ambient temperature collected in the Meteological Station of Ngaoundere on the 15th of January 2014 by M. Tenkeng 
Table 3. Thermodynamic properties of the cycle at 12.30 PM.

\begin{tabular}{|c|c|c|c|c|c|c|}
\hline$i$ & $T(i){ }^{\circ} \mathrm{C}$ & $h(i)(\mathrm{kJ} / \mathrm{kg})$ & $s(i)(\mathrm{KJ} / \mathrm{kg} \cdot \mathrm{K})$ & $m(i)(\mathrm{Kg} / \mathrm{s})$ & $X(i)(\%) \mathrm{LiBr}$ & $\Psi(\hat{i})(\mathrm{kJ} / \mathrm{kg})$ \\
\hline 1 & 35.00 & 81.45 & 0.4625 & 0.1836 & 52.0 & 48.271 \\
\hline 2 & 35.00 & 81.36 & 0.2630 & 0.1836 & 52.0 & 48.271 \\
\hline 3 & 64.00 & 138.47 & 0.3869 & 0.1836 & 52.0 & 51.463 \\
\hline 4 & 115.20 & 135.41 & 0.5012 & 0.1836 & 52.0 & 77.120 \\
\hline 5 & 137.10 & 240.23 & 0.5124 & 0.1591 & 55.0 & 111.324 \\
\hline 6 & 46.50 & 132.14 & 0.2658 & 0.1578 & 60.0 & 88.251 \\
\hline 7 & 46.50 & 132.14 & 0.2658 & 0.1578 & 60.0 & 88.251 \\
\hline 8 & 80.35 & 191.42 & 0.4857 & 0.1591 & 55.0 & 84.120 \\
\hline 9 & 80.35 & 191.42 & 0.4857 & 0.1591 & 55.0 & 84.120 \\
\hline 10 & 137.10 & 2712.58 & 6.8636 & 0.0245 & 00.0 & 19.102 \\
\hline 11 & 89.65 & 365.95 & 1.2011 & 0.0245 & 00.0 & 0.965 \\
\hline 12 & 35.00 & 365.95 & 1.2412 & 0.0245 & 00.0 & 0.183 \\
\hline 13 & 81.45 & 2638.41 & 8.5834 & 0.0133 & 00.0 & 3.220 \\
\hline 14 & 81.45 & 192.17 & 0.4658 & 0.1458 & 60.0 & 101.241 \\
\hline 15 & 35.00 & 145.25 & 0.5124 & 0.0378 & 00.0 & 0.122 \\
\hline 16 & 6.00 & 145.25 & 0.5326 & 0.0378 & 00.0 & -0.598 \\
\hline 17 & 6.00 & 2612.4 & 8.9236 & 0.0378 & 00.0 & -16.330 \\
\hline 18 & 147.00 & 167.22 & 5.8768 & 0.5500 & - & 98.210 \\
\hline 19 & 141.00 & 163.45 & 5.6789 & 0.5500 & - & 85.118 \\
\hline 20 & 25.00 & 103.79 & 0.3586 & 0.2500 & - & -7.140 \\
\hline 21 & 31.15 & 124.28 & 0.3978 & 0.2500 & - & -4.222 \\
\hline 22 & 16.00 & 60.26 & 0.1879 & 0.4000 & - & 24.145 \\
\hline 23 & 9.00 & 39.89 & 0.1145 & 0.4000 & - & 30.811 \\
\hline 24 & 25.00 & 103.79 & 0.3586 & 0.2800 & - & 1.398 \\
\hline 25 & 31.15 & 124.28 & 0.4127 & 0.2800 & - & 4.976 \\
\hline
\end{tabular}

Table 4. The effectiveness for each component at 12.30 PM.

\begin{tabular}{cc}
\hline Component & Effectiveness \\
\hline Generator I & 0.37 \\
Generator II & 0.33 \\
Condenser & 0.68 \\
Evaporator & 0.74 \\
Absorber & 0.78 \\
\hline
\end{tabular}

et al. [19]. Table 2 presents the temperature of the components of the system at 12.30 PM. Table 3 shows the thermodynamic properties of each of the points within the cycle, enthalpy, entropy and exergy at 12:30 PM can be slightly compared to that obtained by Omer Kaynakli et al. [13] for the different points of the system. The values of the exergy for the two studies are similar. Table 4 shows the effectiveness of the two generators, the absorber, the evaporator and the 
condenser. It is noted that the first effect generator GI is a component with a low effectiveness. This indicates that the generator needs a particular attention and must be optimized. Figure 1 shows the variation of insolation during the day chosen for our study. This curve has the same behavior with that of the ambient temperature shown in Figure 3. The variation of the exergy loss of the whole system with the temperature of the first effect generator GI is presented in Figure 4. While the temperature of GI increases, the exergy loss decreases. The lowest exergy loss is obtained for a generator temperature of $150^{\circ} \mathrm{C}$, the maximum temperature for the second effect generator powered by solar energy [13]. Figure 5 shows the variation of the ambient temperature with the maximum value at $12.30 \mathrm{PM}$. The temperature of the solar collector has the same behavior. Figure 6 and Figure 7 show the variation of the COP and ECOP respectively with the temperature of the first effect generator GI. The COP and ECOP depend on the generator load Qge and the evaporator load Qev. The COP decreases almost nonlinearly while the temperature of GI increases. This is a general

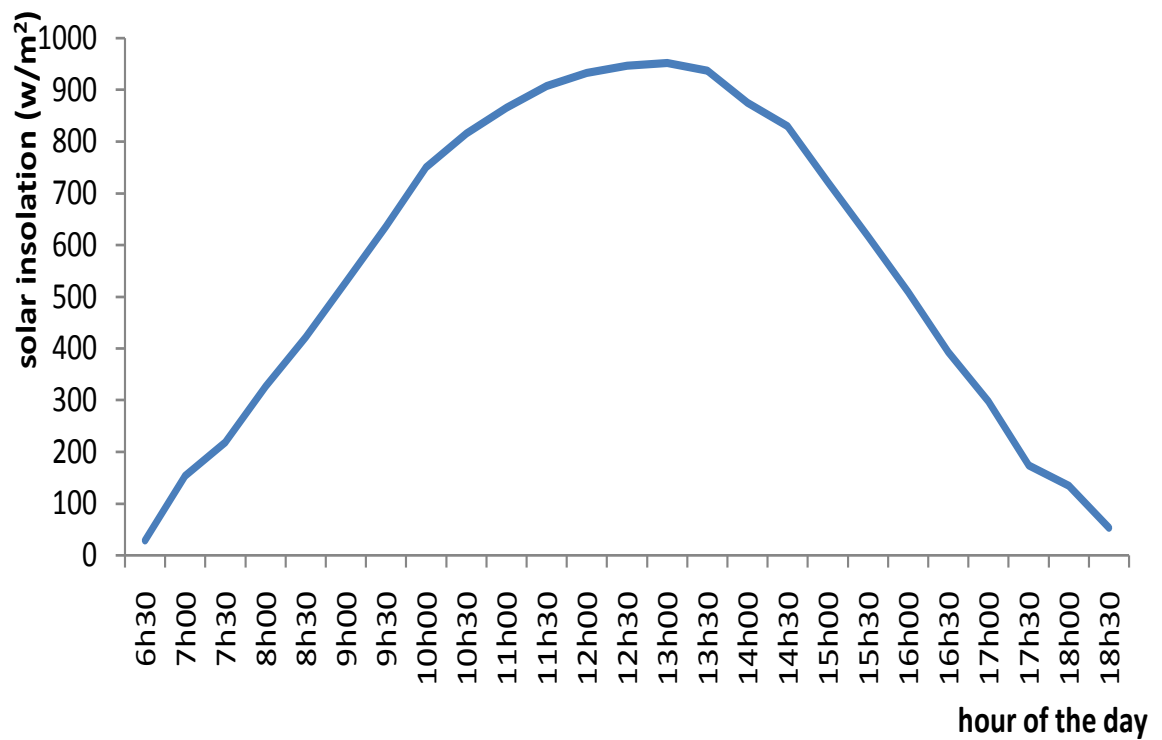

Figure 3. Variation of solar insolation during the day.

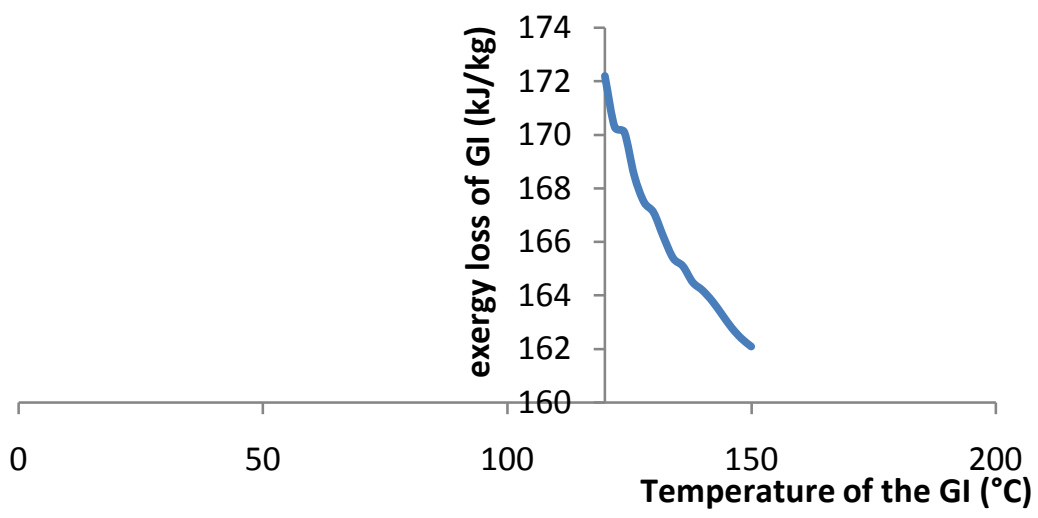

Figure 4. Variation of the exergy loss of GI with the temperature of GI. 


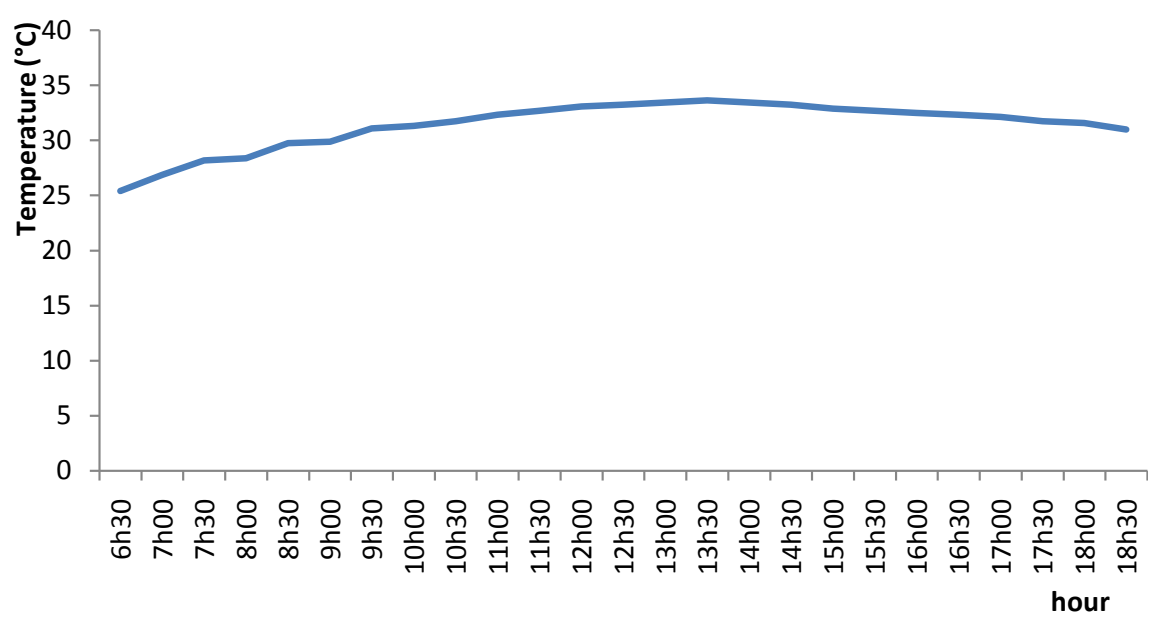

Figure 5. Variation of the ambient temperature during the day.

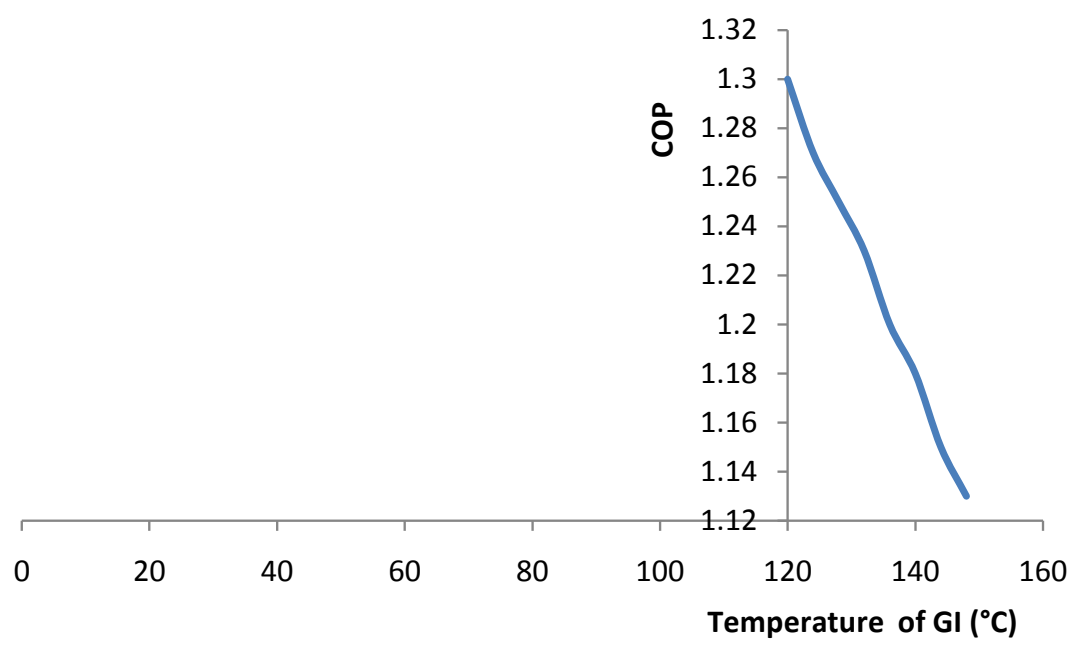

Figure 6. Variation of the COP with the temperature of GI.

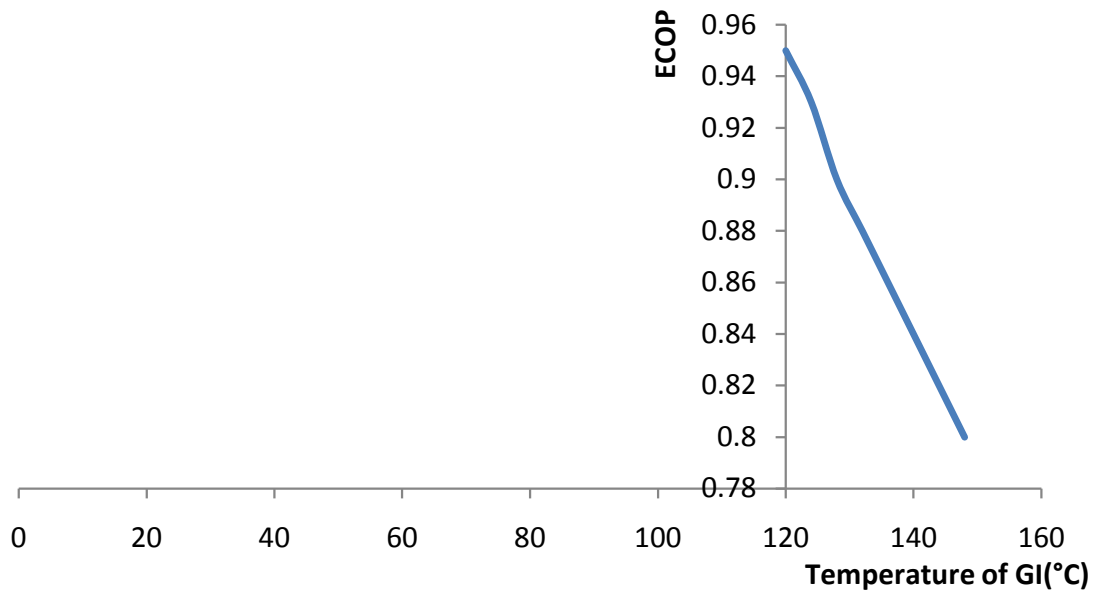

Figure 7. Variation of ECOP with the GI temperature.

behavior of Absorption Refrigeration Systems between the COP and the temperature of the generator receiving the main energy (GI). The ECOP is a very 


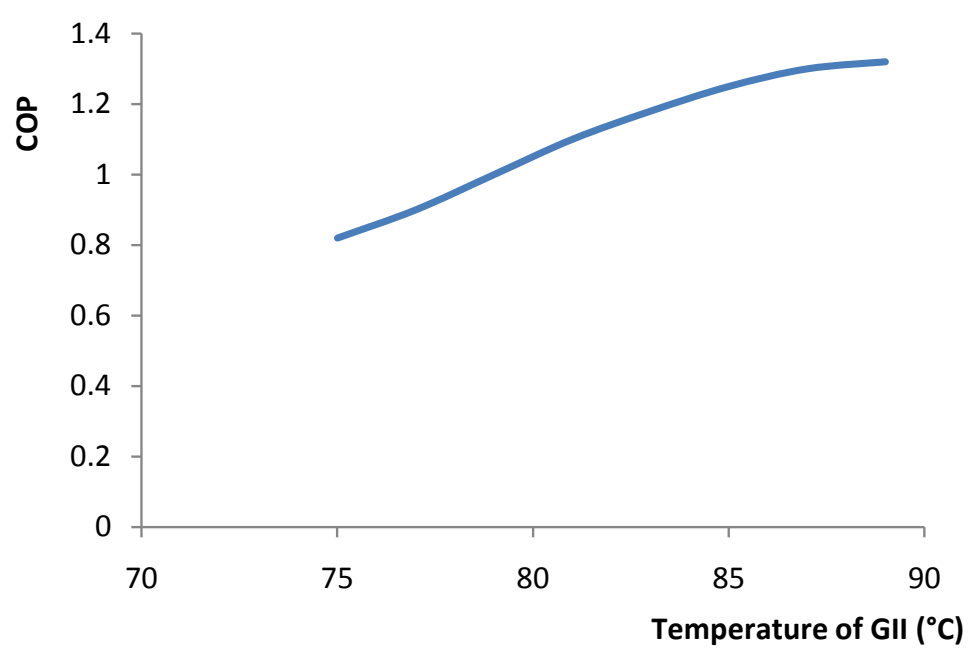

Figure 8. Variation of the COP with the temperature of GII.

important tool for the evaluation of the performance of a system while applying the second law of thermodynamics. The ECOP decrease when the temperature of the first effect generator increase with a minimum value of ECOP which is 0.8 , result in accordance with the litterature. Figure 8 shows the variation of the $\mathrm{COP}$ with the temperature of GII, the COP increases when the temperature increases. This result is in adequation with the need of the second generator in the double effect series flow absorption refrigeration system. So, the main impact of the second generator is to increase the value of the COP of the system.

\section{Conclusions}

By applying the first and the second laws of thermodynamics, the exergy analysis of a double-effect series flow solar absorption refrigeration system, with the most commun working pair, that is $\mathrm{LiBr}-\mathrm{H}_{2} \mathrm{O}$, has been performed under weather conditions of Ngaoundere, in Cameroon, of the 15th January 2014. The study was made throughout the middle of the dry season. The exergy loss of the absorption cooling device and half hourly exergy destruction values of components were determined. The COP and the ECOP of the system were also investigated. The main conclusions obtained from the present study are as follows:

1) The maximum exergy destruction occuring in the solar energy assistance system is in the generator and the evaporator.

2) The exergy loss in the generator indicated that the generator is the component that needs to optimise.

3) The COP and ECOP variation with the temperature of the generators brings us to the conclusion that the second generator has a great contribution to the double effect refrigeration system. The system can therefore be implemented in Cameroon and in countries with high solar availability.

Our study can serve as preliminary investigation to solar water with cooled double effect absorption refrigeration system in tropical cities, and it is necessary to provide a foundation for further researches. 


\section{Conflicts of Interest}

The authors declare no conflicts of interest regarding the publication of this paper.

\section{References}

[1] Allouhi, A., Kouskso, T., Jamil, A., Bruel, P., Mourad, Y. and Zeraouli, Y. (2015) Solar Driven Cooling Systems: An Updated Review. Renewable and Sustainable Energy Reviews, 44, 159-181. https://doi.org/10.1016/j.rser.2014.12.014

[2] Ullah, K.R., Saidur, R., Ping, H.W., Akikur, R.K. and Shuvo, N.H. (2013) A Review of Solar Thermal Refrigeration and Cooling Methods. Renewable and Sustainable Energy Reviews, 24, 499-513. https://doi.org/10.1016/j.rser.2013.03.024

[3] Sözen, A. and Yücesu, H.S. (2007) Performance Improvement of Absorption Refrigeration System Using Triple-Pressure-Level. Renewable Energy, 32, 267-284.

[4] Lior, N. and Zhang, N. (2007) Energy, Exergy, and Second Law Performance Criteria. Energy, 32, 281-296. https://doi.org/10.1016/j.energy.2006.01.019

[5] Talukdar, K. and Gogoi, T.K. (2016) Exergy Analysis of a Combined Vapor Power Cycle and Boiler Flue Gas Driven Double Effect Water-LiBr Absorption Refrigeration System. Energy Conversion and Management, 108, 468-477.

https://doi.org/10.1016/j.enconman.2015.11.020

[6] Said, S.A.M., El-Shaarawi, M.A.I. and Siddiqui, M.U. (2015) Analysis of a Solar Powered Absorption System. Energy Conversion and Management, 97, 243-252. https://doi.org/10.1016/j.enconman.2015.03.046

[7] Ravikumar, T.S., Suganthi, L. and Samuel, A.A. (1998) Exergy Analysis of Solar Assisted Double Effect Absorption Refrigeration System. Renewable Energy, 14, 55-59. https://doi.org/10.1016/S0960-1481(98)00047-0

[8] Bouaziz, N. and Lounissi, D. (2015) Energy and Exergy Investigation of a Novel Double Effect Hybrid Absorption Refrigeration System for Solar Cooling. International Journal of Hydrogen Energy, 40, 13849-13856. https://doi.org/10.1016/j.ijhydene.2015.05.066

[9] Avanessian, T. and Ameri, M. (2014) Energy, Exergy, and Economic Analysis of Single and Double Effect $\mathrm{LiBr}-\mathrm{H}_{2} \mathrm{O}$ Absorption Chillers. Energy and Buildings, 73, 26-36. https://doi.org/10.1016/j.enbuild.2014.01.013

[10] Ashouri, M., Ahmadi, M.H., Pourkiaei, S.M., Astaraei, F.R., Ghasempour, R., Ming, T. and Hemati, J.H. (2017) Exergy and Exergo-Economic Analysis and Optimization of a Solar Double Pressure Organic Rankine Cycle. Thermal Science and Engineering Progress, 6, 72-86.

[11] Zhang, K., Zhu, Y.T., Liu, J.X., Niu, X.F. and Yuan, X.L. (2017) Exergy and Energy Analysis of a Double Evaporating Temperature Chiller. Energy \& Buildings, 165, 464-471.

[12] Gomri, R. (2010) Investigation of the Potential of Application of Single Effect and Multiple Effect Absorption Cooling Systems. Energy Conversion and Management, 51, 1629-1636. https://doi.org/10.1016/j.enconman.2009.12.039

[13] Kaynakli, O., Saka, K. and Kaynakli, F. (2015) Energy and Exergy Analysis of a Double Effect Absorption Refrigeration System Based on Different Heat Sources. Energy Conversion and Management, 106, 21-30. https://doi.org/10.1016/j.enconman.2015.09.010

[14] Maryami, R. and Dehghan, A.A. (2017) An Exergy Based Comparative Study between LiBr/Water Absorption Refrigeration Systems from Half Effect to Triple Effect. Applied Thermal Engineering, 124, 103-123. https://doi.org/10.1016/j.applthermaleng.2017.05.174 
[15] Li, Z., Ye, X. and Liu, J. (2014) Performance Analysis of Solar Air Cooled Double Effect $\mathrm{LiBr} / \mathrm{H}_{2} \mathrm{O}$ Absorption Cooling System in Subtropical City. Energy Conversion and Management. Energy Conversion and Management, 85, 302-312. https://doi.org/10.1016/j.enconman.2014.05.095

[16] Hamed, A., Kaseb, S.A. and Hanaf, A.S. (2015) Prediction of Energetic and Exergetic Performance of Double-Effect Absorption System. International Journal of Hydrogen Energy, 40, 15320-15327. https://doi.org/10.1016/j.ijhydene.2015.05.150

[17] Gomri, R. and Hakimi, R. (2008) Second Law Analysis of Double Effect Vapour Absorption Cooler System. Energy Conversion and Management, 49, 3343-3348. https://doi.org/10.1016/j.enconman.2007.09.033

[18] Sharshir, S.W., Elsheikh, A.H., Peng, G., Yang, N., El-Samadony, M.O.A. and Kabeel, A.E. (2017) Thermal Performance and Exergy Analysis of Solar Stills-A Review. Renewable and Sustainable Energy Reviews, 73, 521-544. https://doi.org/10.1016/j.rser.2017.01.156

[19] Tenkeng, M., Wouagfack, P.A.N., Lissouck, D. and Tchinda, R. (2017) Exergy Analysis of a Solar Absorption Refrigeration System in Ngaoundere. Journal of Power and Energy Engineering, 5, 1-18. https://doi.org/10.4236/jpee.2017.510001

[20] Atmaca, I. and Yigit, A. (2003) Simulation of Solar-Powered Absorption Cooling System. Renewable Energy, 28, 1277-1293.

https://doi.org/10.1016/S0960-1481(02)00252-5

[21] Xu, Z.Y., Wang, R.Z. and Wang, H.B. (2015) Experimental Evaluation of a Variable Effect LiBr-Water Absorption Chiller Designed for High-Efficient Solar Cooling System. International Journal of Refrigeration, 59, 135-143.

[22] Lizarte, R. and Marcos, J.D. (2016) COP Optimisation of a Triple-Effect $\mathrm{H}_{2} \mathrm{O} / \mathrm{LiBr}$ Absorption Cycle under Off-Design Conditions. Applied Thermal Engineering, 99, 195-205. https://doi.org/10.1016/j.applthermaleng.2015.12.121

[23] Anand, S., Gupta, A. and Tyagi, S.K. (2013) Simulation Studies of Refrigeration Cycles: A Review. Renewable and Sustainable Energy Reviews, 17, 260-277. https://doi.org/10.1016/j.rser.2012.09.021

[24] Şencan, A., Yakut, K.A. and Kalogirou, S.A. (2005) Exergy Analysis of Lithium Bromide/Water Absorption Systems. Renewable Energy, 30, 645-657. https://doi.org/10.1016/j.renene.2004.07.006

[25] De Vos, A. (1993) The Endoreversible Theory of Solar Energy Conversion: A Tutorial. Solar Energy Materials and Solar Cells, 31, 75-93. https://doi.org/10.1016/0927-0248(93)90008-Q

[26] Pridasawas, W. and Lundqvist, P. (2004) An Exergy Analysis of a Solar-Driven Ejector Refrigeration System. Solar Energy, 76, 369-379. https://doi.org/10.1016/j.solener.2003.11.004

[27] Sözen, A. (2001) Effect of Heat Exchangers on Performance of Absorption Refrigeration Systems. Energy Conversion and Management, 42, 1699-1716. https://doi.org/10.1016/S0196-8904(00)00151-5

[28] Kaynakli, O. and Kilic, M. (2007) Theoretical Study on the Effect of Operating Conditions on Performance of Absorption Refrigeration System. Energy Conversion and Management, 48, 599-607. https://doi.org/10.1016/j.enconman.2006.06.005

[29] Mittelman, G., Kribus, A. and Dayan, A. (2007) Solar Cooling with Concentrating Photovoltaic/Thermal (CPVT) Systems. Energy Conversion and Management, 48, 2481-2490. https://doi.org/10.1016/j.enconman.2007.04.004 


\section{Nomenclature}

$C O P$ : coefficient of performance

ECOP: exergy coefficient of performance

f. circulation ratio

$h$ : enthalpy $(\mathrm{kJ} / \mathrm{kg})$

$s$. entropy $(\mathrm{kJ} / \mathrm{kgK})$

m: mass flow rate $(\mathrm{kg} / \mathrm{s})$

$Q$ : heat flow rate $(\mathrm{kW})$

T: temperature $\left({ }^{\circ} \mathrm{C}\right.$ or $\left.\mathrm{K}\right)$

$P$ : pressure $(\mathrm{kPa})$

$\psi$. exergy $(\mathrm{kJ} / \mathrm{kg})$

$x$. mass fraction of lithium bromide (\%)

\section{Subscripts}

i: component $\mathrm{i}$

ref: reference

g: ge: generator

e: ev: evaporator

a: ab: absorber

c: co: condenser

hex: heat exchanger

ev: expansion valve

pump: p: pump

$\mathrm{p}$ : planet

ws: w: weak solution

sc: solar collector

s: solution or system

sc, r: solar collector radiation

h: heat

p: planet

HEX I: heat exchanger

HEX II: heat exchanger

SEV: solution expansion valve

S1: weak solution at the inlet of GI

S2: weak solution at the inlet of GII

W: work

REV: refrigerant expansion valve

u: useful

ava: available.

sun: sun 